\title{
A methodology to obtain the block size distribution of fragmental rockfall deposits
}

\author{
Roger Ruiz-Carulla ${ }^{1}$, Jordi Corominas ${ }^{1}$, Olga Mavrouli ${ }^{1}$
}

\begin{abstract}
Rock masses detached as rockfalls usually disintegrate upon impact on the ground surface. The knowledge of the Rockfall Block Size Distribution (RBSD) generated in the rockfall deposit is useful for the analysis of the trajectories of the rock blocks, run-out distances, impact energies and for the quantitative assessment of the rockfall hazard. Obtaining the RBSD of a large rockfall deposit may become a challenge due to the high number of blocks to be measured. In this paper, we present a methodology developed for mid-size fragmental rockfalls ( $10^{3}$ up to $10^{5} \mathrm{~m}^{3}$ ) and its application to the Cadí massif, Eastern Pyrenees. The methodology consists of counting and measuring block fragments in selected sampling plots within homogeneous zones in the young debris cover generated by the rockfall along with all the large scattered rock blocks. The size distribution of blocks obtained in the sampling plots is extrapolated to the whole young debris cover and summed to the inventoried large scattered blocks to derive the RBSD of the whole rockfall event. The obtained distributions from the fragments can be well fitted by a power law distribution, indicating the scale invariant character of the fragmentation process (Hartmann 1969 ; Turcotte, 1986). The total volume of the rockfall fragments has been checked against the volume at the rockfall source. The latter has been calculated comparing 3D digital surface models before and after the rockfall event.
\end{abstract}

Keywords: rockfall, fragmental rockfall, block size distribution, volume estimation

\section{Introduction}

Evans and Hungr (1993) and Hungr et al. (2014) reserved the term fragmental rockfall, for the events in which the individual fragments move as independent rigid bodies interacting with the ground surface by means of episodic impacts. They distinguished it from the term rock avalanche in which masses of fragments move in a flow-like way. In fragmental rockfalls, the detached rock mass, which often includes discontinuities, disaggregates, breaks or both, after the first impacts on the ground. The resultant fragments propagate independently downhill. The deposit of a fragmental rockfall is a set of rock blocks of different sizes scattered on the ground surface. In the case of mid to large-size fragmental rockfalls (more than thousands of cubic meters) a more or less continuous Young Debris Cover (YDC) can be formed as well (Fig. 1). Understanding the fragmentation process is fundamental for the analysis of the rockfall hazard, since it is a critical input datum for calculating the trajectories and the run-out of the rock fragments, the encounter probability with the elements at risk and the expected impact energies.

The importance of the rockfall fragmentation in the analysis of the rockfall hazard has been discussed by Jaboyedoff et al. (2005) and Corominas et al. (2012). The definition of the initial rockfall volume is crucial when performing the trajectographic analysis. Run-out analyses performed with the originally detached rock mass volume produce results, which are significantly different from those using individual rock blocks (Okura et al., 2000 ; Dorren 2003). Considering the initial rock mass leads to the overestimation of the rockfall kinetic energy and run-out. If the modal or the maximum block fragment size is used instead, the travel distances and the energies obtained are more realistic. However, the frequency and the impact probability are largely underestimated as in reality, the original rock mass splits into a large number of rock fragments, leading to the multiplication of the impact probability by a factor " $n$ " equal to the number of new blocks generated. Taking this into consideration, the assessment of the size and number of blocks produced from an original rock mass is of primary importance for the rockfall risk analysis (Hungr et al. 1999). An indicator of the rockfall fragmentation is given by the Rockfall Block Size Distribution (RBSD).

\footnotetext{
${ }^{1}$ Technical University of Catalonia (UPC), Department of Geotechnical Engineering and Geosciences, Barcelona: roger.ruiz@upc.edu ; jordi.corominas@upc.edu ; olga-christina.mavrouli@upc.edu
} 


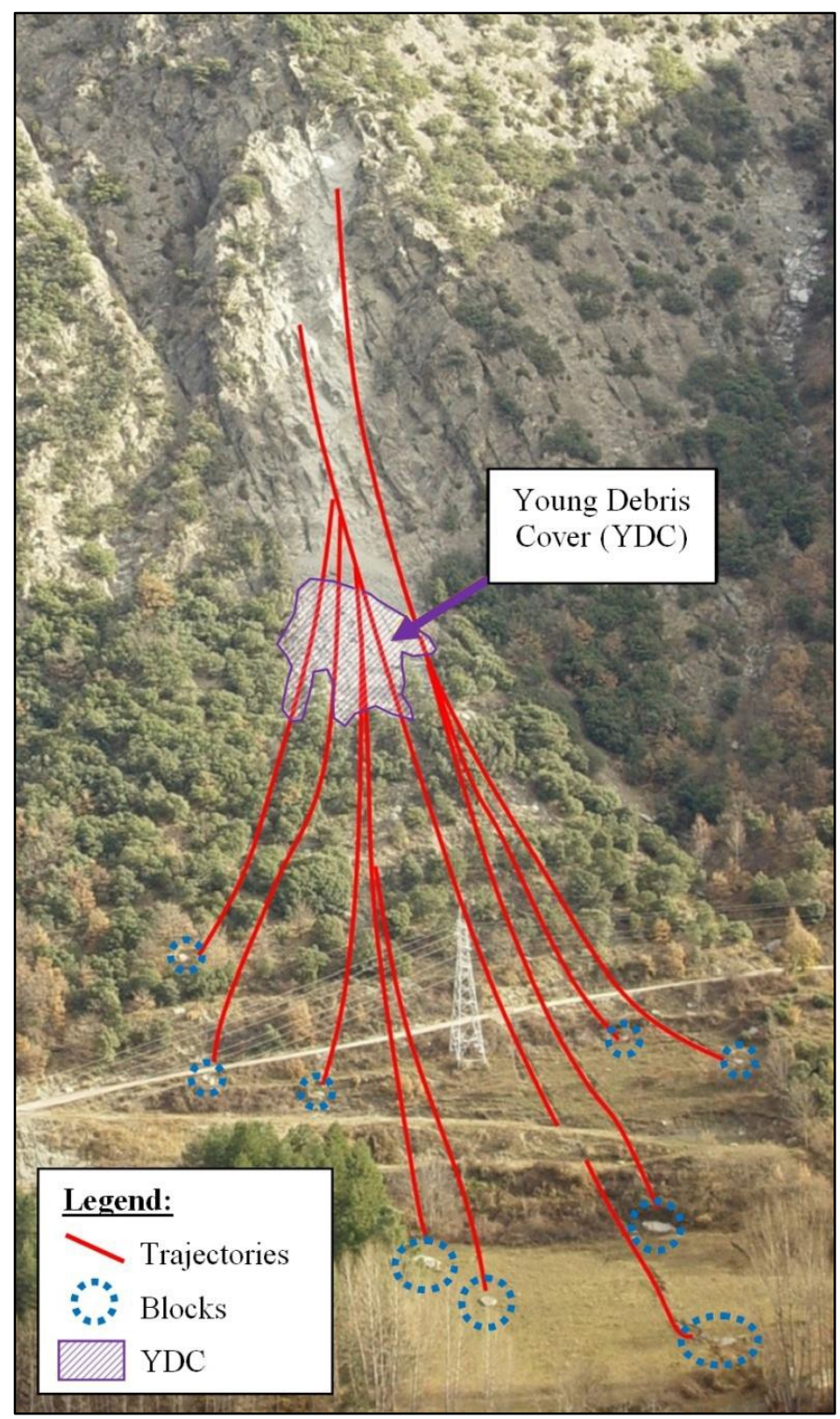

Fig. 1. Fragmental rockfall at La Guingueta, Central Pyrenees, Spain. The trajectories of the large scattered blocks diverge after the impact of the rock mass upon the ground surface. A young debris cover, composed of small-size blocks, has been deposited close to the rockfall source.

Several parameters influence the fragmentation process and the RBSD (Dussauge et al. 2003; Wang \& Tonon 2010; Hantz et al 2014): the presence of discontinuities in the detached rock mass as well as their persistence, aperture and orientation at the moment of the impact, the impact energy, the rigidity of the ground and the impact angle. However, rockfall fragmentation is a complex physical mechanism that it is still poorly understood and difficult to simulate (Chau 2002; Zhang et al. 2000). A few codes incorporate a fragmentation module for propagation analysis such as HY-STONE (Agliardi \& Crosta 2003). It includes a trained neural network (HechtNielsen 1987; Schalkoff 1997) which determines the mass and velocities of the fragments right after the impact. The model is efficient in predicting whether a rock block is broken or not on given impact conditions. It can also approximate well the energy loss due to the failure process and the energy transformation upon impact. However, it has some difficulties in reproducing the fragment size distribution as observed in reality. Salciarini et al. (2009) used a Discrete Elements Model approach to model the fragmentation effects using the software UDEC, and the results of the simulations indicated that the position and the extent of the accumulation zone is strongly affected by rock mass fragmentation. Tests performed in quarries provided some insight into the phenomenon but were not able to indicate impact energy thresholds that produce breakage of the blocks (Giacomini et al. 2009). The observations of Dussauge et al. (2003) suggest that the rockfall fragment sizes are associated with the fracture pattern of the detached rock mass volume at the source. Hantz et al. (2014) found that the deposited rockfall blocks follow a power law. 
The investigation of the rockfall phenomenon for the development of predictive models requires the existence of rockfall inventories. Commonly, the rockfall inventories record the total volume of the detached mass (Dussauge et al. 2002, 2003) or the largest blocks with the longest run out. Complete inventories including deposited blocks of all sizes are difficult to obtain. Several researchers mainly working on rock blasts, have used photoanalytical techniques to obtain the fragment size distribution (Crosta et al. 2007). However these provide results only for the block area and not for the volume. In large rockfall deposits, the large amount of blocks and the extent of the deposits make difficult obtaining the RBSD. To this end, field work should be systematic and well-organized. In this paper we present a methodology to obtain the RBSD based on field measurements.

\section{Methodology}

Mid-size fragmental rockfalls often generate a more or less continuous young cover of small debris and larger scattered blocks (Fig. 2). Some debris covers have a large extent and display a progressive downhill increase of the average block size. Because of this, obtaining the RBSD may become a challenging task.

Two complementary activities may be performed for measuring the rock blocks and obtaining the RBSD: a) the selective sampling of the young debris cover (YDC); and b) the systematic measurement of the large scattered blocks. The methodology is summarized in Fig. 2.

First, the YDC is divided into homogeneous zones of similar average block size based on visual field observation and orthophoto interpretation (in this case, A1 to A3). At each zone, several sampling plots are defined in which all the blocks larger than a minimum size are measured to obtain the respective block size distribution of the plot. The large scattered blocks are georeferenced using a GPS GARMIN Montana 650 and measured one by one. A few small blocks outside the YDC were also measured and included in this group. Three lengths more or less orthogonal to each other are measured at each block to estimate the volume, assuming that the shape of the blocks is prismatic.

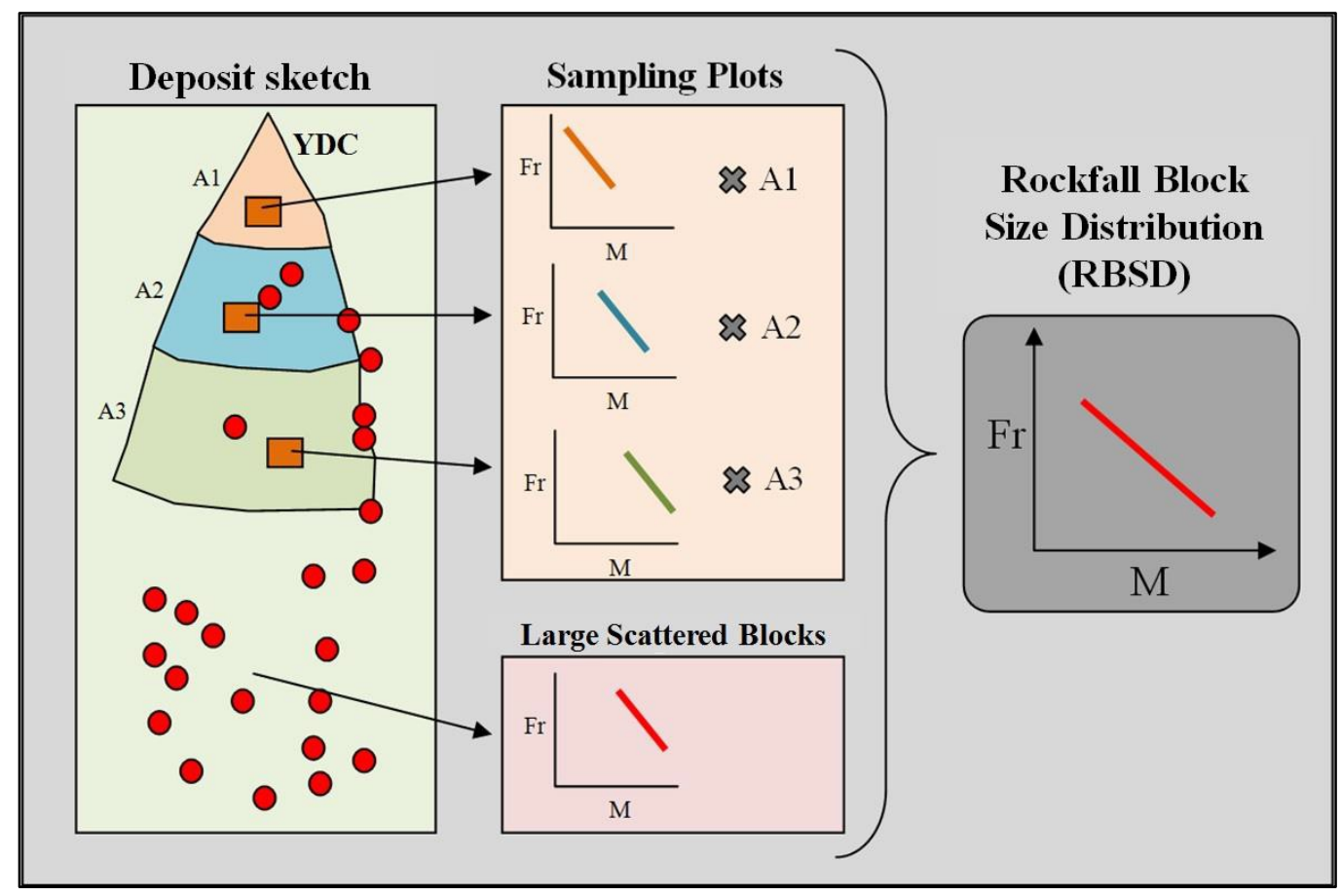

Fig. 2: Methodology followed to prepare the RBSD. The scheme shows the Young Debris Cover (YDC), the sampling plots (orange squares) for each homogeneous zone A1 to A3 (the symbol X stands for weighted multiplication, see step 2 in the text below), and the large scattered blocks. The plots display the block size distribution where "Fr" is the cumulative relative frequency for each block size bin "M".

The RBSD is obtained as follows (Fig. 2):

(1) The measured blocks of each sampling plot (orange squares) are classified in bins (j) of different block size ranges. It is convenient to test several bin ranges before choosing one of them (see Clauset 2007), in order to define correctly the shape of the distribution (specially the tail). 
(2) Then, the block size distribution for each sampling plot is extrapolated to the whole homogeneous zone. The extrapolation is done for each defined zone ( $i$ ) (for example, in the methodology scheme of the Fig.2 $i=3$ ), multiplying the number of measured blocks of each block size bin $\left(n\left(V_{j}\right)_{i}\right.$ ) with a scaling factor $R_{i}(E q .1)$ :

$$
n\left(V_{j}\right)^{R B S D}=n\left(V_{j}\right)^{\text {measured }} \cdot R_{i} \quad(\text { Eq.1) }
$$

Where.: $n\left(Y_{j}\right)_{i}^{R B S D}$ : is the number of blocks in the block volume bin $(j)$ representing the zone (i) in the RBSD; $n\left(V_{j}\right)_{i}^{\text {meàsured }}:$ is the number of measured blocks in the block volume bin $(j)$ in the zone $(i)$; The scaling factor $R_{i}$ is defined as:

$$
R_{i}=\frac{A_{i}}{A^{s p}} \quad \text { (Eq. 2) }
$$

$R_{i}$ : is the scaling factor; $A_{i}$ : is the area of the homogeneous zone $(i) ; A^{s p_{i}}$ : is the area of the sampling plot selected in the zone (i).

(3) The block size distribution of the Large Scattered Blocks (LSB) is prepared independently. The LSB includes only individual blocks, and does not represent a continuous surface covered by blocks. Hence the LSB distribution is not extrapolated.-

(4) Finally, the RBSD is obtained by adding al the afore-mentioned distributions.

$$
R B S D: n\left(V^{j}\right)^{R B S D}=\sum_{i=1}^{i} n\left(V^{j}\right)^{R B S D}+n^{L S B}\left(V^{j}\right)
$$

Where $n\left(V_{j}\right)^{R B S D}$ : is the estimated number of blocks in the block volume bin $(j)$ in the RBSD representative of the whole deposit; $n\left(V_{j}\right)_{i}{ }^{\text {BSD }}$ : is the estimated number of blocks in the block volume bin $(j)$ in each defined zone $i$; $n_{L S B}\left(V_{j}\right)$ : is the number of Large Scattered Blocks in the block volume bin $(j)$. Finally, the obtained RBSD can be represented either in terms of cumulative number of blocks or as relative frequency.

Several constraints must be overcome. In case that rockfall fragments stop over a previously existing talus slope, only the new deposited blocks associated to the recent event are measured. A key issue is thus differentiating young from old rock fragments. When the reconnaissance is made shortly after the occurrence of the event, this should not be a difficulty. New blocks show distinct fresh broken surfaces, including faces with stained coatings and clay fills, and bright colours (Fig. 3 and 4). If the YDC is formed by a thick continuous deposit in which a percentage of blocks are buried and cannot be measured, then the counting becomes uncertain and this becomes a restriction of the proposed approach.

The definition of the homogeneous zones is based on visual field observation and orthophoto interpretation. It is recommended to select more than one sampling plots at each homogeneous zone in order to double check the distribution obtained. The influence of the number of homogenous zones and the selection of the sampling plots is discussed at section 4(d). The length of the sampling plots must be at least one order of magnitude greater than the length of the measured blocks. Consequently, the area of the sampling plots increases with the size of the blocks. Big boulders found in the YDC are considered large scattered blocks when they are more than one order of magnitude bigger than the rest of the blocks. 


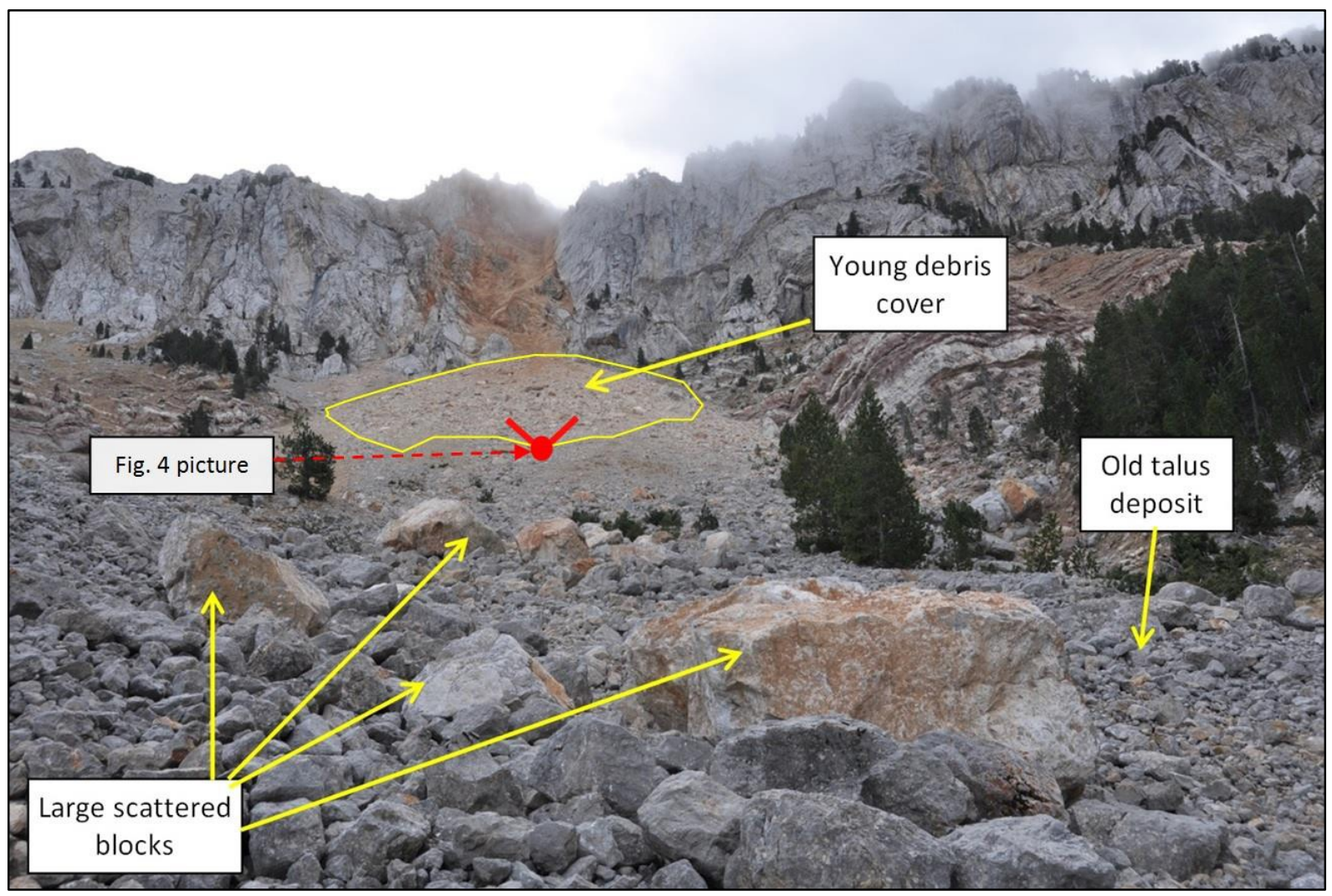

Fig. 3: Large scattered blocks laying on a previously existing talus deposit. New blocks stand out from the old ones by their most vivid (reddish, yellowish) colours. An almost continuous young debris cover is noticeable at the background. The red dot is the location of the picture in Figure 4. Vilanova de Banat rockfall at the Cadí massif, Eastern Pyrenees.

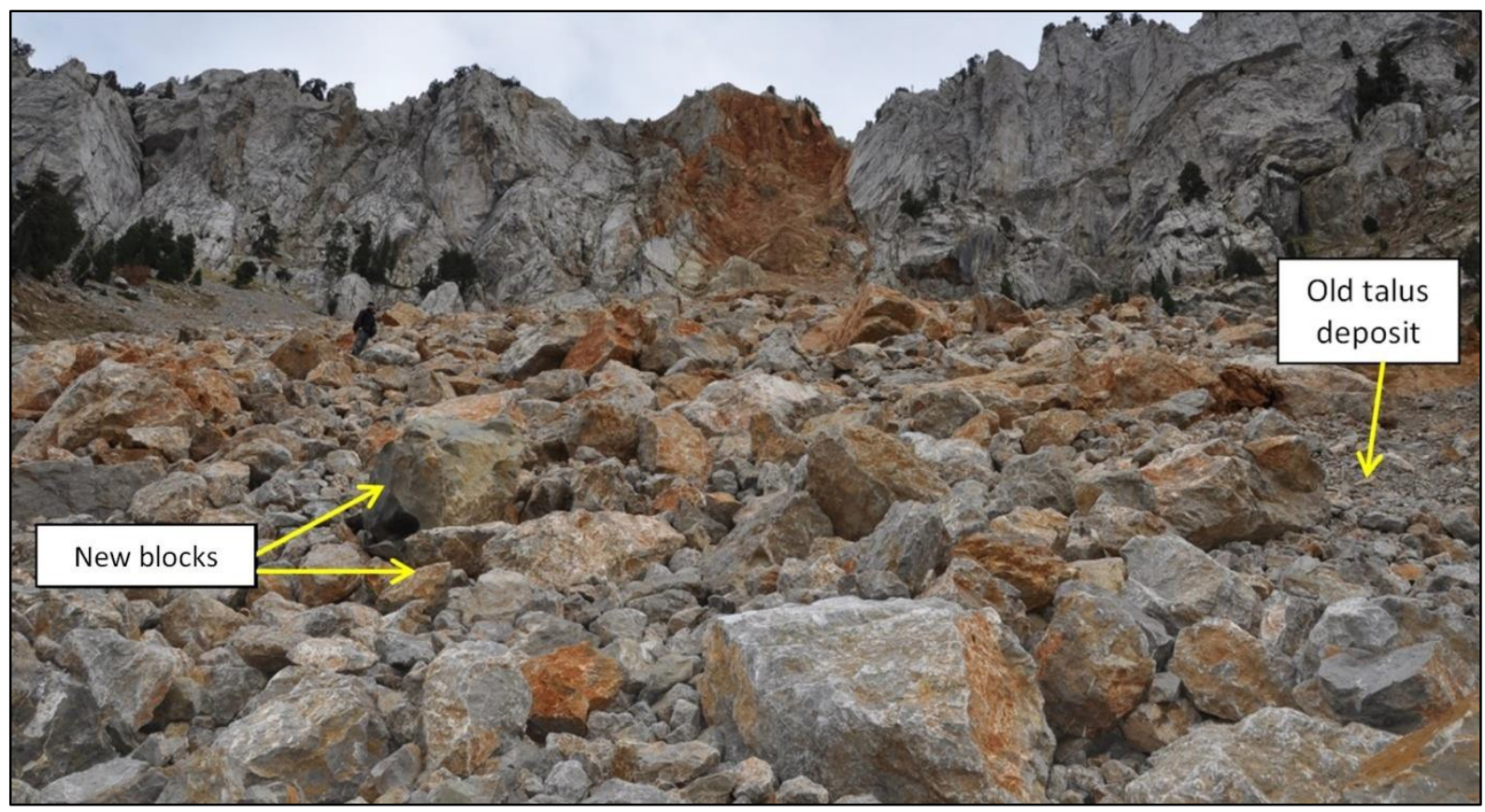

Fig. 4: View of the lower zone of the YDC. Almost continuous debris cover generated by the Vilanova de Banat rockfall, lying on a previously existing talus deposit. New blocks stand out from the old ones by their most vivid colours (reddish, yellowish). Distinct fresh fractures and spalling as a consequence of the impacts are also observed. 


\section{Application to a case-study}

The proposed methodology has been applied to obtain the RBSD of a mid-size fragmental rockfall event occurred near the village Vilanova de Banat in November 2011, on a limestone cliff in the Cadí Sierra, Eastern Pyrenees (Fig. 3 and Fig 4). The rockfall has an initially estimated detached mass of about $10000 \mathrm{~m}^{3}$ (Fig. 5a, red line). The source area measures 40 meters in width, 40 meters in height (from $2270 \mathrm{~m}$ to $2310 \mathrm{~m}$ of altitude) and 14 meters in thickness approximately, and it has a wedge shape. A 3D model of the source area and the potentially detachable mass is presented in section 5 .

The YDC covers an area of approximately $30000 \mathrm{~m}^{2}$ extended between the altitudes of $1950 \mathrm{~m}$ and $2138 \mathrm{~m}$, with a maximum length of 260 meters and a maximum width of 115 meters (yellow line in Fig. 5b). The YDC is an almost continuous layer of boulders of variable size, between few decimeters in the upper zone of the talus up to one meter in the lowest zone.
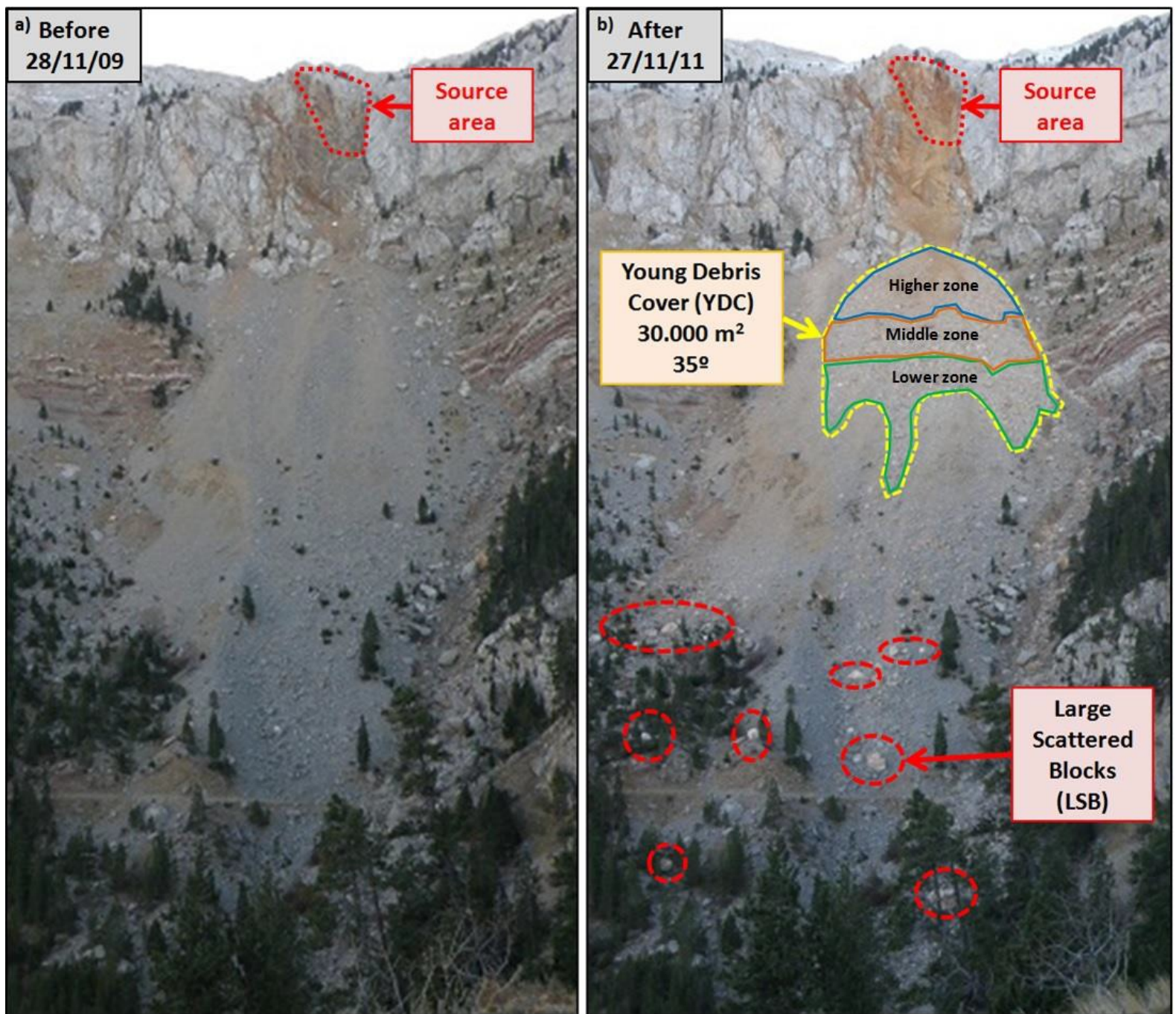

Fig. 5: Rockfall event occurred in November 2011 in Cadí massif, Eastern Pyrenees. 5a shows the rockfall source area before the occurrence of the rockfall event. $5 b$ shows the same area after the rockfall event, including the source area (dashed red line), the young debris cover (dashed yellow line) formed in the upper zone of the talus and the large scattered blocks (dashed red ellipses) deposited in the lower zone of the talus.

Three roughly homogeneous block size zones have been visually identified: the higher, middle and lower zone of the YDC. We further divided the zones in sectors in order to check their size-homogeneity and select sampling plots (SP1 to SP6 in Fig. 6). Table 1 shows the area of the sampling plots (that varies between $25 \mathrm{~m}^{2}$ and $400 \mathrm{~m}^{2}$ ) and the number of blocks measured in each SP. A total of 1500 blocks larger than $0.015 \mathrm{~m}^{3}$ were measured, which includes both the large scattered blocks (272), and the blocks inside the sampling plots (1252). Block sizes under $0.015 \mathrm{~m}^{3}$ were not measured due to their large number and because many of them were lost in voids existing among large older blocks. The locations of each large block, and of the corners of the sampling plots, were georeferenced with a GPS. 


\section{Results}

The deposit of the November 2011 rockfall event was mapped including the location of all the measured large scattered blocks, the sampling plots, the delimitation of the defined sectors and the source area (Fig. 6).

\section{(a) Large Scattered Blocks}

The large scattered blocks (LSB: green dots in Fig. 6) were mainly found in the western part of the deposit (inside a predominant trajectory path), and also in the lower zone of the deposit, with larger run out than the YDC. Some very big blocks found in the YDC were also considered LSB when they are at least one order of magnitude larger than the rest of the blocks in the sampling plot. The volume of the biggest measured boulder is $30.8 \mathrm{~m}^{3}$, and the measured maximum runout distance from the source area is 683 meters.

\section{(b) Sampling Plots}

The sampling plots 1, 2, 3 and 4 are located in the higher and middle zones in the young debris cover. The sampling plots 1 and 2 have an area of $100 \mathrm{~m}^{2}$, while the sampling plots 3 and 4 of $25 \mathrm{~m}^{2}$. The sampling plots 3 and 4 were selected to double check the mesurements of the highest zone where sampling plot 2 is found. The sampling plots 5 and 6 , which are located at the lowest part of the YDC, have a predominance of big blocks, and their areas are larger, $400 \mathrm{~m}^{2}$ and $225 \mathrm{~m}^{2}$ respectively. We used two sampling plots in the lower zone to double check the block size distribution of the YDC.

\section{(c) Block size distributions}

The blocks measured in each sampling plot, as well as the blocks measured as large scattered blocks, were plotted in the Fig. 7, in terms of cumulative number of blocks versus block volume. We tested different bin ranges. The shape distributions obtained using 5, 12 and 19 bins were compared to the original distribution. Our results show low precision shape of distribution using 5 bins, whereas using 12 or 19 the shape is well defined. Based on these results we finally classify the blocks in bins as $0.01-0.02 ; 0.02-0.05 ; 0.05-$ 0.1 ; 0.1-0.2 ; 0.2-0.5; 0.5-1 ; $1-2$; 2-5 ; 5-10 ; 10 20 and 20-50, all of them in cubic meters, covering 4 orders of magnitude.

These block size distributions obtained directly from the measurements in the sampling plots have a very similar slope in a log-log plot, and can be well fitted by power laws. In section $4(d)$ we have performed a sensitivity analysis of the final RBSD with respect to the SP used (using 6, 4 or 3 SP).

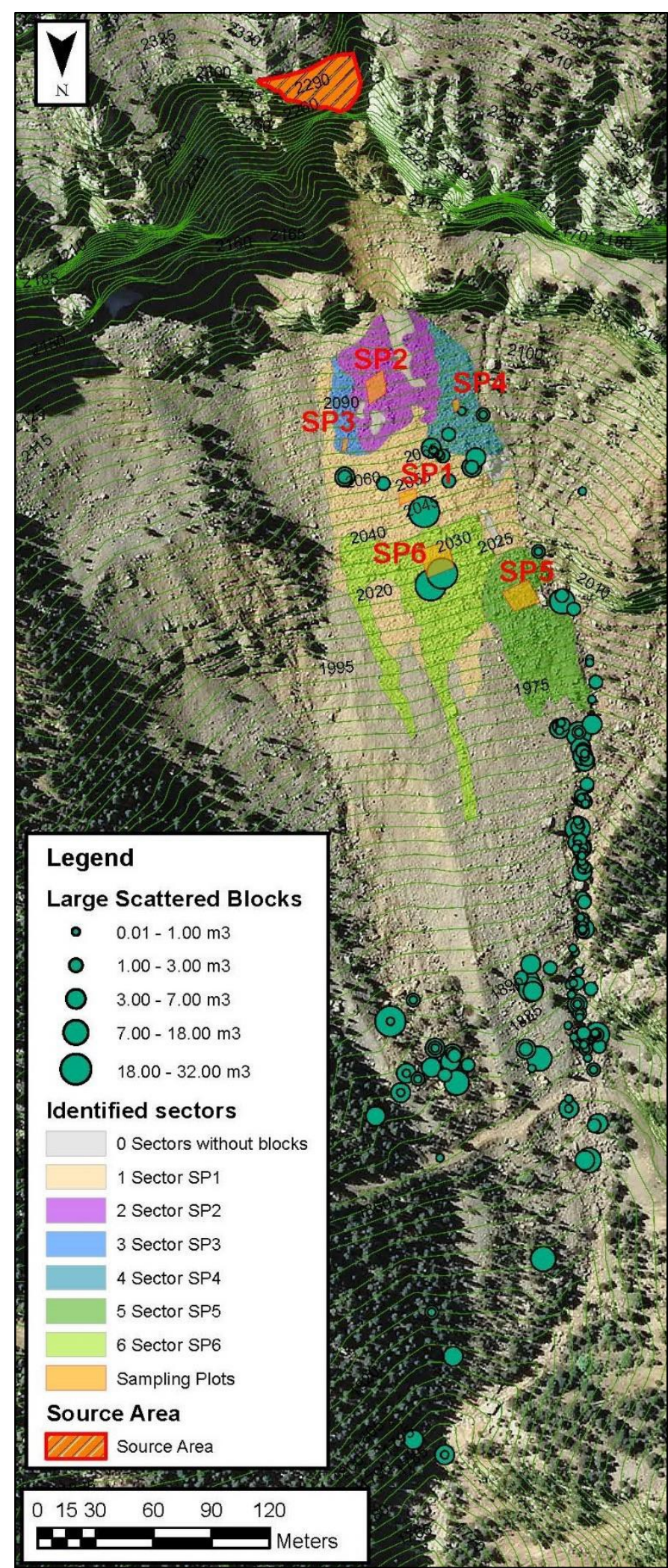

Fig. 6: Orthophoto map showing the location of the six homogeneous sectors of the YDC, sampling plots, the large scattered blocks, and the source area. 


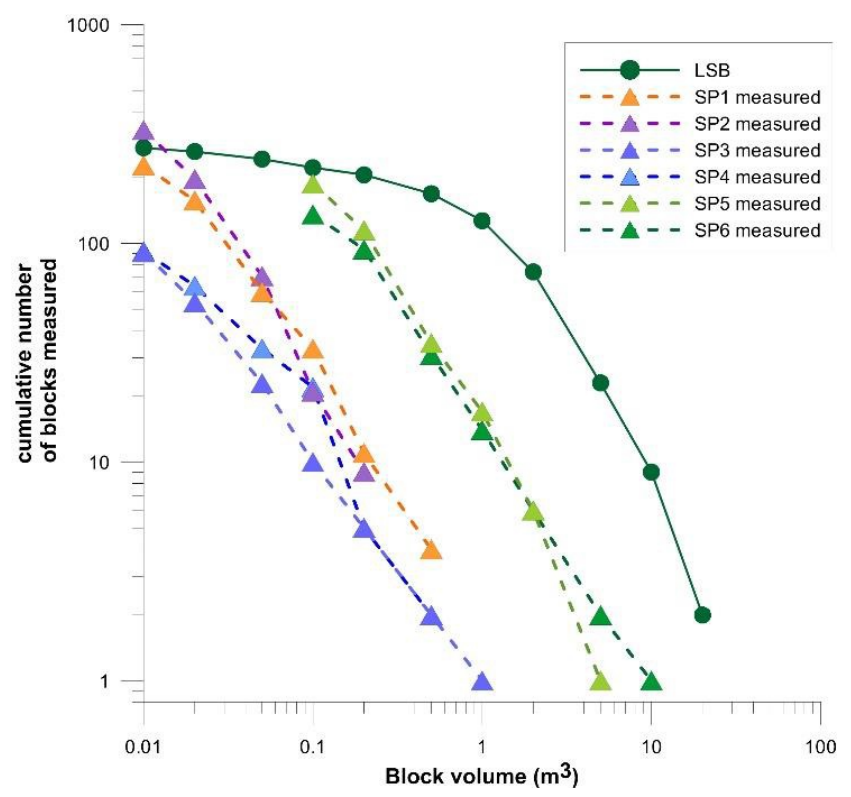

Fig. 7. Cumulative number of blocks measured versus block volume obtained directly from the measurements in the sampling plots (SP) and from the large scattered blocks (LSB)

Figure 7 shows that the block size distributions from the highest zone of the YDC (SP2, SP3 and SP4) are very similar to each other and also to SP1 (middle zone). Furthermore, SP5 and SP6 show a substantial overlap confirming the size homogeneity of the lowest unit of the YDC. It is noticeable that the slope of the obtained distributions is similar for all of them. The measured volumes cover a range of 4 orders of magnitude without gaps.

We classified the data in bins to extrapolate the block size distributions from the sampling plots to the corresponding homogeneous sectors, using the scaling factor for each defined sector (Fig. 8). Adding all of them and the large scattered blocks distribution we obtain the final RBSD representative of the whole deposit, allowing the estimation of the total volume of the rock mass detached. Table 1 shows the scaling factors used to extrapolate the data from the sampling plots to the homogeneous sectors. The extrapolated data, the fitted power laws by linear regression, and the resultant RBSD obtained, are shown in the Fig. 8.

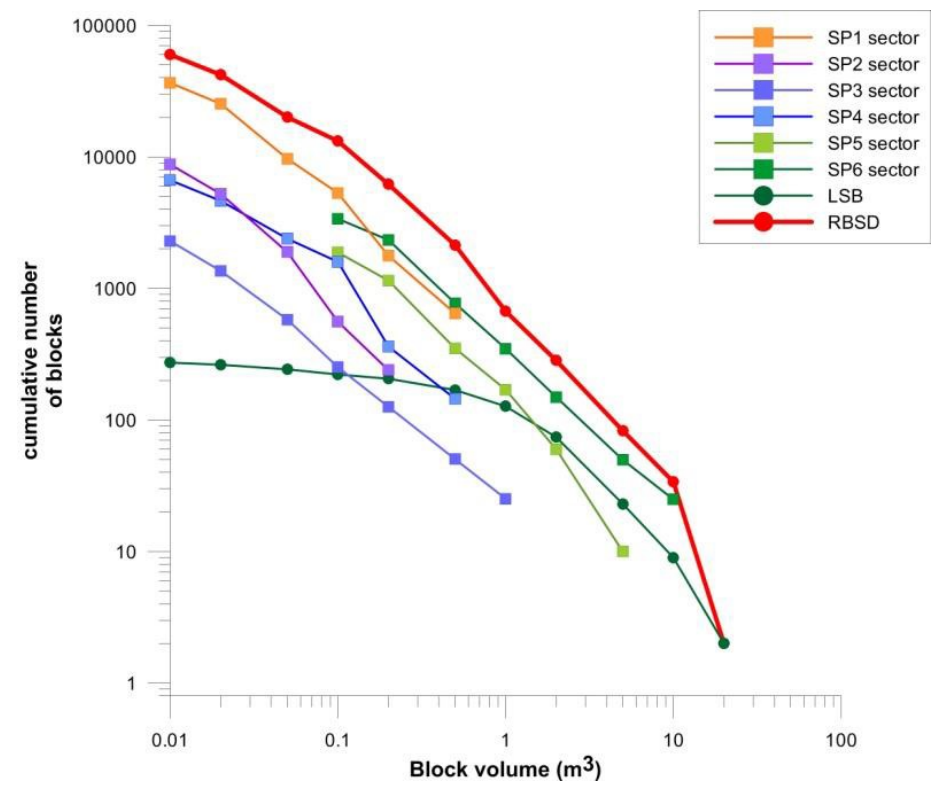

Fig. 8: Block size distributions obtained from the extrapolation of the measurements using the areas ratios, in terms of cumulative number of blocks versus block volume. The obtained RBSD is representative of the whole deposit. The power laws fitted to these distributions are also represented.

The minimum total volume of the rockfall deposit calculated with this procedure is approximately $8000 \mathrm{~m}^{3}$, involving more than 60000 blocks over $0.015 \mathrm{~m}^{3}$, based on the data plotted in the Fig. 8. 
As a final step, the same block size distributions shown in the Fig. 8 were expressed in terms of cumulative relative frequency. The frequency $\left(\mathrm{F}_{\mathrm{r}}\right.$ or P) block size $\left(V_{o}\right)$ distributions (Fig. 9) of the sampling plots and the large scattered blocks can be also fitted by power laws (Dussauge et al. 2002 ; Crosta 2007) characterized by: a) a constant $C$ associated with the minimum significant block size $\left(V_{\min }\right)$, and $\left.\mathrm{b}\right)$ an exponent $b$ which is the slope of the distribution in a log-log representation (Eq. 4).

$$
P\left(V_{\min } \leq V_{o}\right)=C \cdot V_{o}^{-b} \quad \text { Eq. } 4
$$

To estimate the exponent, $b$ value, we used the linear regression method and the maximum likelihood estimator because they are the two methods classically suggested in the literature (Dussauge 2003 ; Pickering et al, 1995 ; Clauset et al, 2009). A minimum block size is used to fit the power law to each distribution. Table 2 shows the obtained $C$ and $b$ values and the minimum volume used for each frequency - block size distribution plotted in the Fig. 9. The exponent $b$ of the fitted power laws ranges between 0.8 and 1.3 obtained using the linear regression method, and between 0.8 and 1.2 obtained using the maximum likelihood estimator method. The fitted power laws using the linear regression show a very good fitting with $\mathrm{R}^{2}$ ranging between 0.94 and 0.98 . The values of the reduced $\chi_{r}{ }^{2}$ test for the fitted power laws (using both methods) range between 0.010 and 0.014 (Table 2), significantly lower than 1 .

Therefore the proposed power laws describing the global RBSD can be well accepted given the reduced $\chi_{r}^{2}$ values of 0.222 and 0.082 for the linear regression and the maximum likelihood methods respectively. The final RBSD obtained was fitted by a power law with $\mathrm{C}=0.01$ and $b=1.26$ using the linear regression method, and a $\mathrm{C}=0.01$ and $b=1.16$ using the maximum likelihood method.

The SP and LSB data represented in the Fig. 9 are plotted block by block in cumulative frequency terms. To obtain the RBSD a previous classification of the data in bins was made to extrapolate the data and to sum it up. This figure, and the same block density of the sectors of each defined zone (Table 1), confirms that the visual selection of the homogeneous zones was appropriate. The block size distributions of SP5 and SP6 show a perfect overlap. For SP2, SP3 and SP4 collected in the highest zone only the SP4 shows a slight shift. In any case, the difference in frequency is less than one order of magnitude for most of the sizes.

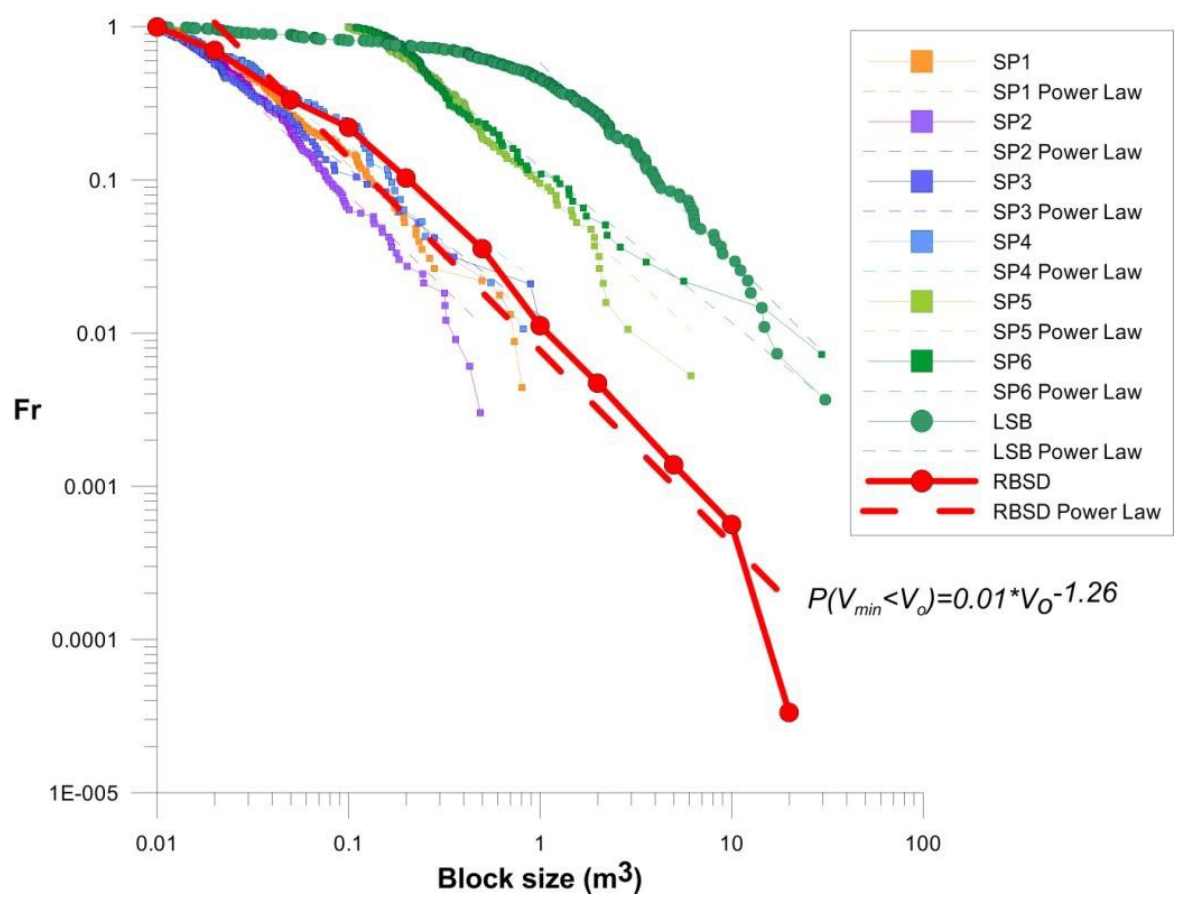

Fig.9: Block size distribution obtained from the 6 sample plots: SP1-6; from the large scattered blocks: LSB; the obtained Rockfall Block Size Distribution: RBSD, and the fitted power law by linear regression method.

The frequency - block size distributions in the Cadí case (Fig. 9) cannot be extrapolated for volumes bigger than the biggest blocks found. Therefore the right end of the total RBSD is determined by the maximum block volume measured, while the extrapolation to the left end is restricted by the total volume of the rock mass detached. For rockfall events bigger than the November 2011 event, the frequency - block size distribution can be used to calculate 
the probability of having blocks bigger than a given volume. Fig. 10 shows the frequency - block size distribution and the fitted power laws by the linear regression and the maximum likelihood method. It may be observed that the linear regressions yield relative frequencies greater than 1 for block sizes close to the minimum volume used (SP1, SP4, SP5 or RBSD), which does not make sense. This occurs because the method is not able to impose the condition $F r=1$ when $V o l=V_{\min }$. This drawback does not appear when using the maximum likelihood method. In the RBSD case, if the $X_{r}$ test is used to minimize the error of the fitting, this condition is not fulfilled, maybe due to a rollover effect in blocks size under $0.1 \mathrm{~m}^{3}$.

Table 1: Summary of blocks measured, area of the sampling plots, area of the homogeneous sectors and scaling factors.

\begin{tabular}{|c|c|c|c|c|c|}
\hline & $\begin{array}{l}\mathrm{N}^{\circ} \text { of blocks } \\
\text { measured }\end{array}$ & $\begin{array}{c}\text { SP area } \\
\left(\mathbf{m}^{2}\right)\end{array}$ & $\begin{array}{c}\text { Area of the } \\
\text { homogeneous sector } \\
\left(\mathbf{m}^{2}\right)\end{array}$ & $\begin{array}{c}\text { Block } \\
\text { Density } \\
\left(\mathbf{n}^{0} \text { blocks } / \mathbf{m}^{2}\right)\end{array}$ & $\begin{array}{c}\text { Scaling factor } \\
\mathbf{R}\end{array}$ \\
\hline SP1 & 284 & 100 & 16125 & 2.84 & 161.3 \\
\hline SP2 & 400 & 100 & 2659 & 4.00 & 26.6 \\
\hline SP3 & 113 & 25 & 629 & 4.52 & 25.2 \\
\hline SP4 & 103 & 25 & 1810 & 4.12 & 72.4 \\
\hline SP5 & 209 & 400 & 3994 & 0.52 & 10 \\
\hline SP6 & 143 & 225 & 5610 & 0.64 & 24.9 \\
\hline LSB & 272 & - & - & - & - \\
\hline $\begin{array}{l}\text { TOTAL } \\
\text { RBSD }\end{array}$ & 1524 & $\begin{array}{r}875 \mathrm{~m}^{2} \\
60231\end{array}$ & $\begin{array}{c}30830 \mathrm{~m}^{2} \\
\text { aber of blocks calcula }\end{array}$ & $y$ the extrapola & \\
\hline
\end{tabular}

Table 2: Obtained values of the fitted power laws using Linear Regression and Maximum Likelihood methods.

\begin{tabular}{|c|c|c|c|c|c|c|c|c|c|}
\hline & & \multicolumn{4}{|c|}{ Power Law fitted by Linear Regression } & \multicolumn{4}{|c|}{ Power Law fitted by Maximum Likelihood } \\
\hline & $\begin{array}{c}\text { Min. } \\
\text { Volume } \\
\left(\mathbf{m}^{3}\right)\end{array}$ & $\mathbf{C}$ & b & $\begin{array}{l}\text { Standard } \\
\text { Deviation } \\
\text { for } b(\sigma)\end{array}$ & $\begin{array}{c}\text { Test } \\
\mathbf{X}_{\mathrm{r}}{ }^{2}\end{array}$ & $\mathbf{C}$ & $\mathbf{b}$ & $\begin{array}{l}\text { Standard } \\
\text { Deviation } \\
\text { for } b(\sigma)\end{array}$ & $\begin{array}{c}\text { Test } \\
\mathbf{X}_{\mathrm{r}}^{2}\end{array}$ \\
\hline SP1 & 0.01 & 0.011 & 1.04 & 0.07 & 0.009 & 0.025 & 0.79 & 0.05 & 0.010 \\
\hline SP2 & 0.01 & 0.004 & 1.22 & 0.07 & 0.020 & 0.012 & 0.96 & 0.05 & 0.011 \\
\hline SP3 & 0.01 & 0.013 & 0.96 & 0.10 & 0.002 & 0.014 & 0.91 & 0.09 & 0.010 \\
\hline SP4 & 0.01 & 0.021 & 0.89 & 0.09 & 0.014 & 0.036 & 0.72 & 0.07 & 0.012 \\
\hline SP5 & 0.1 & 0.088 & 1.18 & 0.09 & 0.006 & 0.117 & 0.93 & 0.07 & 0.010 \\
\hline SP6 & 0.1 & 0.121 & 1.02 & 0.09 & 0.004 & 0.157 & 0.83 & 0.07 & 0.010 \\
\hline LSB & 1 & 1 & 1.28 & 0.11 & 0.029 & 1 & 1.06 & 0.09 & 0.007 \\
\hline RBSD & & 0.01 & 1.26 & 0.38 & 0.222 & 0.01 & 1.16 & 0.35 & 0.082 \\
\hline
\end{tabular}

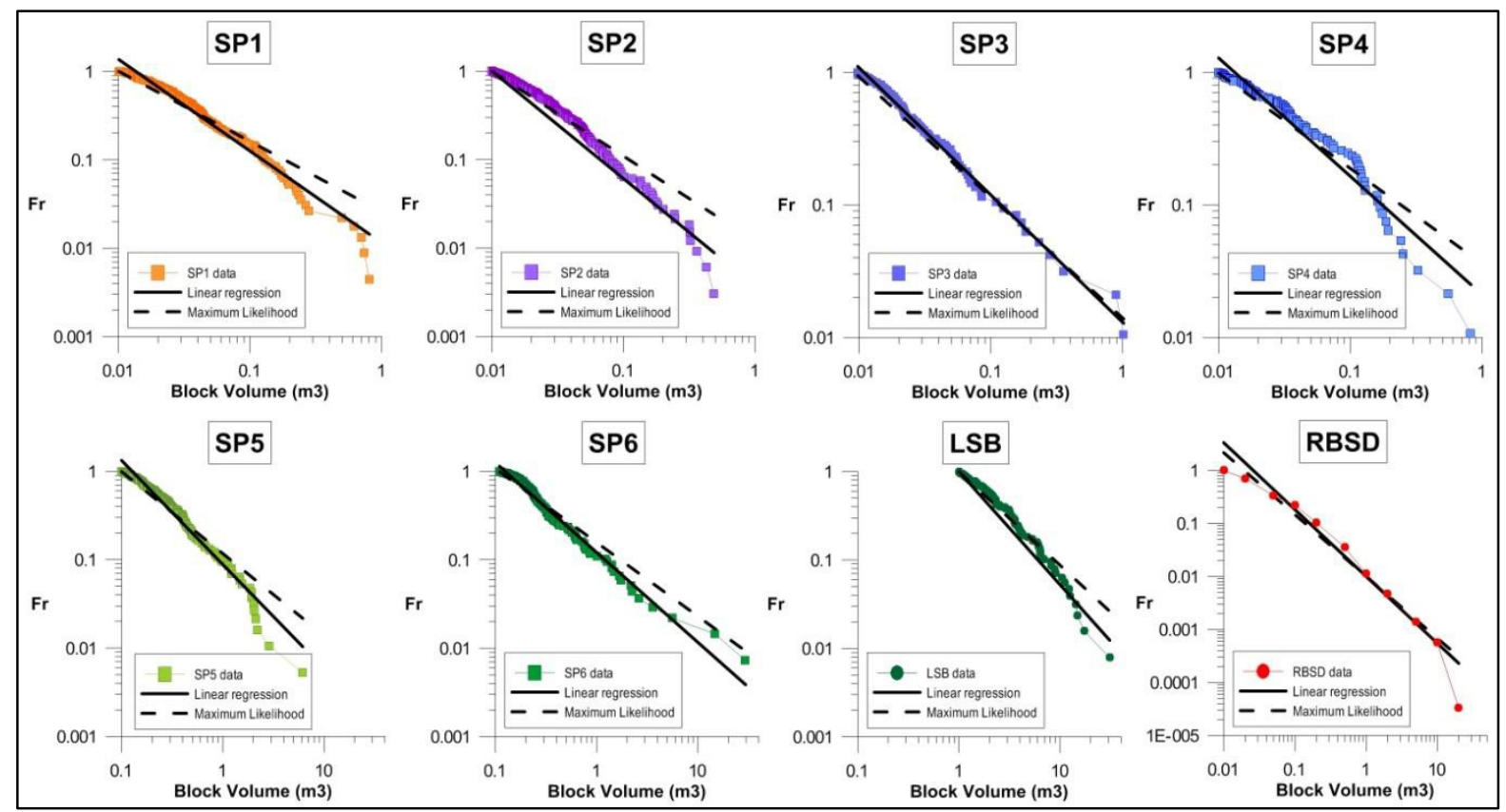

Fig.10: Comparison of the fitted power laws using linear regression or maximum likelihood methods for the frequency - block size distribution for each sampling plot data, the large scattered blocks and the final RBDS. 


\section{(d) Repeatability of the block size distributions obtained in the sampling plots}

The selected sampling plots in the YDC were: SP2, SP3 and SP4 (higher zone); SP1 (middle zone); and SP 5 and SP6 (lower zone). To verify the degree of representativeness and repeatability of the selected sampling plots we have generated several RBSD using alternatively the data of 3, 4 or 6 sampling plots, with the following combinations: SP1, SP2, and SP6; SP1, SP2, SP5 and SP6; and all of them. In all these cases, the LSB distribution is also used. The merged zones have the same block density (Table 1).

The generated RBSDs have similar shapes and are fitted well by power laws (Fig. 11). The obtained exponents range between 1.26 (six sampling plots), 1.25 (four sampling plots) and 1.22 (three sampling plots). The results show that the visual selection of the block-size homogeneous zones and the sampling plots does not produce significant differences in the obtained RBSD.

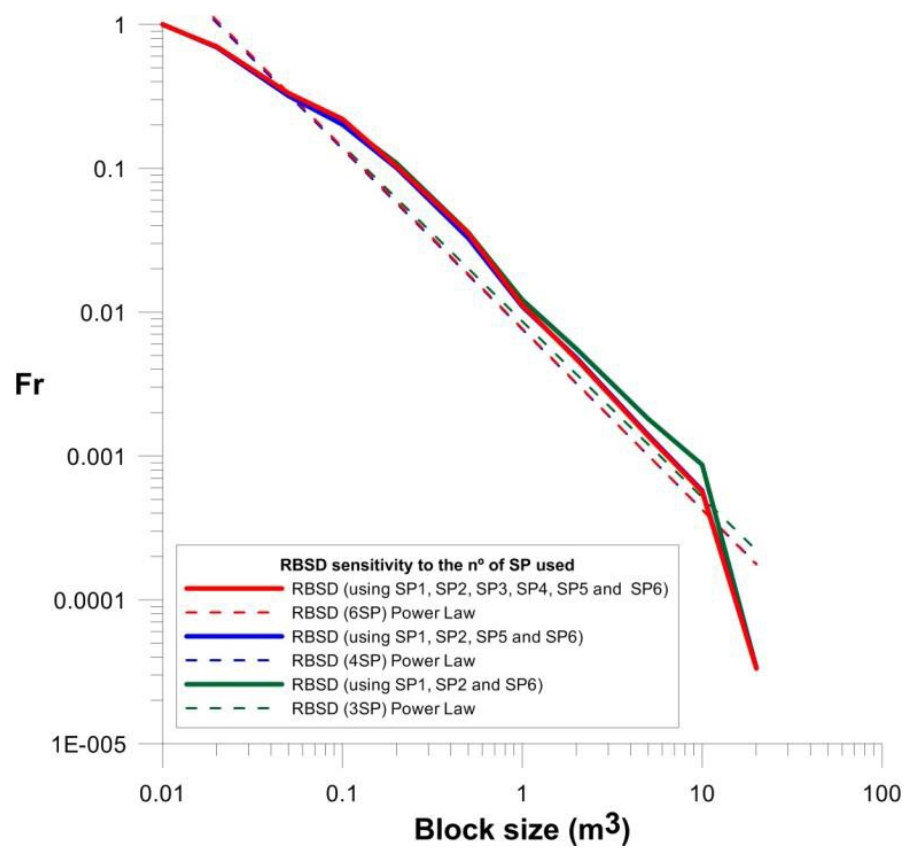

Fig.11: RBSD obtained using six, four or three sampling plots.

\section{Checking the obtained rockfall volume.}

To validate the proposed procedure we used an alternative method to calculate the total detached volume from the cliff for the Cadí rockfall event. The total detached volume obtained with the RBSD was approximately $8000 \mathrm{~m}^{3}$. This corresponds to the minimum volume because blocks smaller than $0.015 \mathrm{~m}^{3}$ were not measured. This value has been checked against the volume obtained subtracting two Digital Surface Models (DSM). We used the topographic model at 1:5000 scale, of the Cartographic Institute of Catalonia, generated by aerial photogrammetry before the rockfall occurrence. To obtain a DSM of the rockfall scar after the rockfall, we used a digital photogrammetry software with pictures taken from the ground.

The use of two consecutive 3D models to estimate a volume detached from a cliff has been discussed before (Sturzenegger et al., 2009; Firpo et al., 2011 ; Viero 2012). The main limitation of this case is that the topographic model is obtained with aerial photogrammetry (with an accuracy of about 1 metre in $\mathrm{X}$ and $\mathrm{Y}$ coordinates, and 1.5 $\mathrm{m}$ in $\mathrm{Z}$ for the $90 \%$ of the defined points). Meanwhile, the photogrammetric model of the scar is realised using terrestrial pictures, taken from a direction which is almost perpendicular to the aerial orthophoto. Consequently, the errors of these models are maximum in different directions. To estimate the detached volume, we proceed with the following steps:

a) We used 17 pictures taken by a camera Nikon D90 with a focal length of $60 \mathrm{~mm}$ and a resolution of 4288x2848px (12Mp).

b) We tested all the pictures using the software Agisoft PhotoScan and VisualSFM. It uses the Structure from Motion algorithms to identify the matching pixels between pictures, thus allowing working with more than two pictures. It also reconstructs the position where the pictures were taken, readjusts the distortion parameters of the 
lens, and generates a 3D point cloud (Wu 2011). The final scar DSM used is a mesh based on the 3D point cloud generated.

c) The DSM of the rockfall scar was scaled and georeferenced using seven Ground Control Points (GCP) (Fig.12). The coordinates of these seven GCP were obtained from the orthophoto and from the topographic maps.

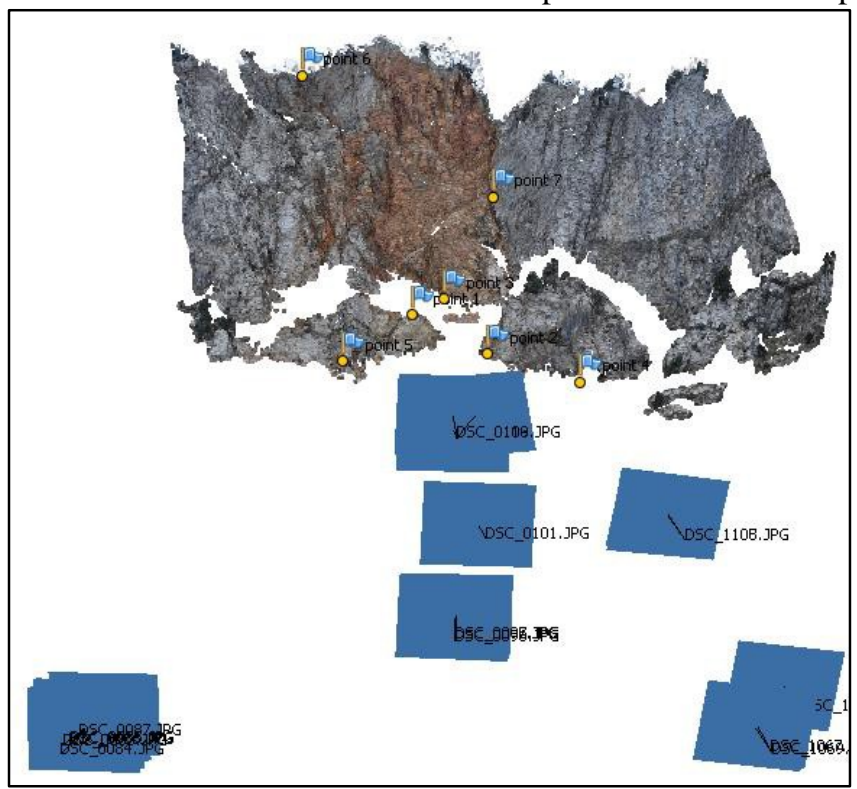

Fig.12: 3D visualisation with the location of the used pictures (blue rectangles) and the Ground Control Points (yellow points)

d) We generated a DSM based on the topographic map at 1:5000 scale prior to the event.

e) Both DSMs have been aligned with the software CloudCompare. To this end, we have first excluded the rockfall detached zone. In this alignment the difference analysis show a distance ranging from 0 to $9.2 \mathrm{~m}$, with a standard deviation of $3.7 \mathrm{~m}$. and a mean distance of $1.1 \mathrm{~m}$. The difference here is attributed to the different precision between the topographic DSM, which includes topographic data smoothing where abrupt rock corners are present, and the scar DSM.

f) Then, a new difference analysis between the scar DSM (including the detached zone) and the topographic DSM show differences ranging between 0 and $18.4 \mathrm{~m}$ (due to inclusion of the detached volume), a standard deviation of $3.2 \mathrm{~m}$ and mean distance of $2.1 \mathrm{~m}$. This difference map (Fig.13b) was used to delineate the detached zone in the cliff (Fig.13a) and to estimate the detached volume.

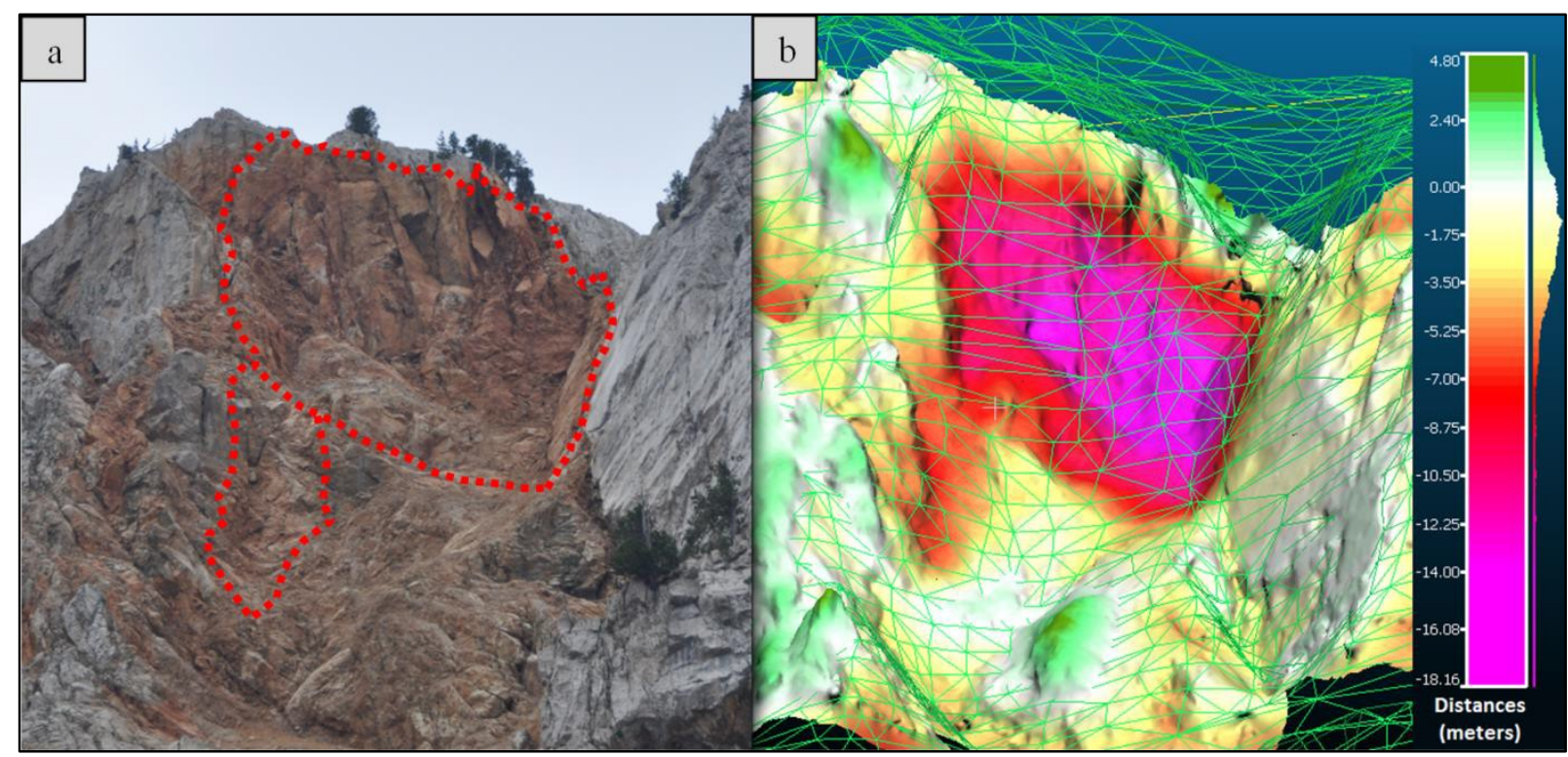

Fig.13: a) Picture of the scar (the rockfall detachment zone is outlined in red). b) Topographic DSM (green mesh), scar DSM coloured by the distances to the topographic DSM. 
g) Finally, we used the software Rhinoceros to define a volume using the topographic DSM, the scar DSM, and two main joints identified in the cliff (Fig. 14). The joints are identified in the pictures and over the scar DSM. Their use allows to define the volume according with the field observations where the recent scar is distinguished by its red colour and fresh faces (Fig.13a).

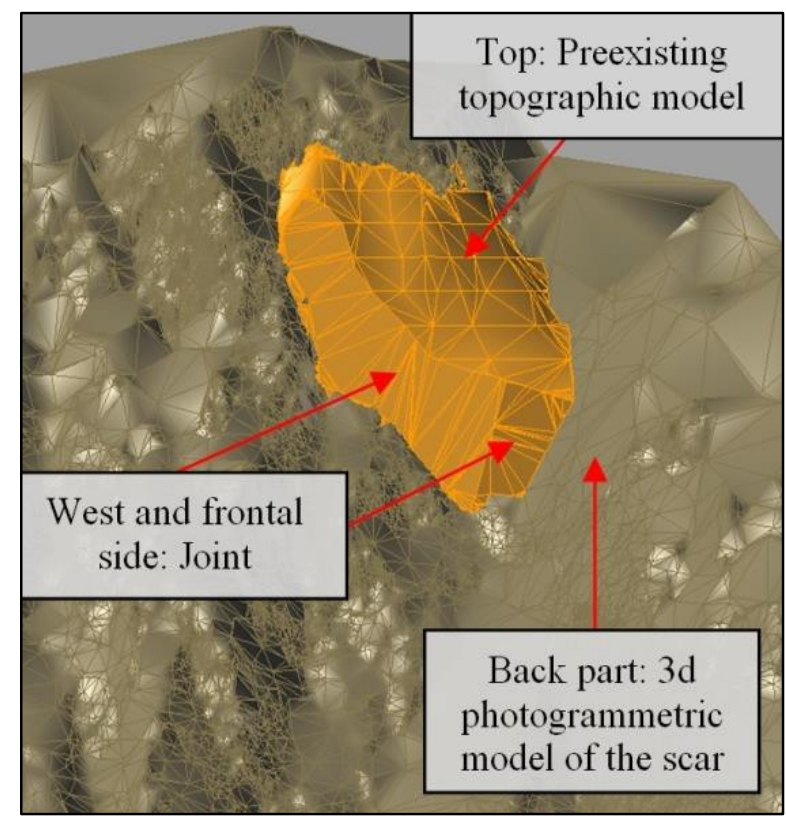

Fig. 14. Detached volume reconstruction (orange volume) based on the topographic DSM (top), the scar DSM coloured in brown (back, laterals and bottom parts) and two main joints (frontal face).

The estimated volume is approximately $10000 \mathrm{~m}^{3}$, which is bigger than the volume based on measured rock fall blocks $\left(8000 \mathrm{~m}^{3}\right)$. The $2000 \mathrm{~m}^{3}$ of difference between both volumes is possibly ought to the fact that approximately the $20 \%$ of the rock mass can result in dust and blocks smaller than $0.015 \mathrm{~m}^{3}$ that were not measured in the field. In fact, by extrapolating the RBSD to a block size of $0.005 \mathrm{~m}^{3}$, a volume of $10000 \mathrm{~m}^{3}$ is obtained. Another possible reason for this difference is the uncertainties and the errors associated to the topographic DSM and the scar DSM.

\section{Conclusions}

The presented sampling-procedure allows the construction of the block size distribution of a fragmental rockfall deposit in a consistent and reliable way. Double checking of the sampling plots has shown that the visual selection of the block-size homogeneous zones was appropriate, obtaining the same block density in the sectors inside each defined zone. The fitted power laws of the RBSD generated using 6, 4, and 3 SP, yielded the following exponents:1.26, 1.25 and 1.22, respectively.

The application to a case study, a mid-size fragmental rockfall deposit in the Eastern Pyrenees, has yielded a RBSD which is well fitted by a power law. In the case of the large scattered blocks, a rollover effect appears related to the voluntary censoring of blocks smaller than $1 \mathrm{~m}^{3}$ at our measurements. The rest of the obtained block size distributions show a sight rollover effect and can be very well fitted directly with power laws. The RBSD for this particular case shows a rollover effect, suggesting that there is bias due to undersampling of the blocks under 0.1 $\mathrm{m}^{3}$, as it occurred in SP5 and SP6.

The obtained power law distributions are consistent with the observations of Hartmann (1969), Perfect (1997) and Turcotte (1986) about fragmentation in rocks, where the number of fragments versus size generated by the fragmentation process follow a power law. The exponent of the fitted power law, is related with the fractal dimension, and could be used as a descriptor of the fragmentation process.

The measured volumes cover a range of 4 orders of magnitude. It is also noticeable that the similar slope of these distributions indicates the homogeneity or the scale invariant behaviour of the samples. The power law related with the block size distribution generated at a fragmental rockfall is truncated on the right branch by the maximum volume block detached and on the left branch, by the minimum sampled volume.

The maximum likelihood method used to fit the RBSD with a power law represent better the whole data than the fit using the linear regression method. However the biggest blocks are better fitted by the linear regression method. 
The power law describing the RBSD can be alternatively calculated excluding bigger volumes as outliers

The total detached volume was estimated $8000 \mathrm{~m}^{3}$ based on the field measurements. This volume was checked against the volume of the rockfall scar. The latter was obtained by subtracting the scar DSM based on terrestrial digital photogrammetry and the DSM derived from the topographic map prior to the event giving a total of 10000 $\mathrm{m}^{3}$. The difference in the two volumes can be attributed to the precision errors of the DSMs. Nevertheless, the extrapolation of the RBSD to block volumes up to $0.005 \mathrm{~m}^{3}$ which were not sampled, can as well compensate for the missing volume.

\section{Acknowledgements}

The authors acknowledge the support of the Spanish Economy and Competitiveness Ministry to the Rockrisk research project (BIA2013-42582-P) and the support of the Ministry of Education to the first author (grant code FPU13/04252)

\section{References}

Agliardi F, Crosta GB (2003) High resolution three-dimensional numerical modelling of rockfalls. Int. Journal of Rock Mechanics \& Mining Sciences 40: 455-471

Chau K T, Wong R H C, Wub, J J (2002) Coefficient of restitution and rotational motions of rockfall impacts. Int. Journal of Rock Mechanics \& Mining Sciences 39: 69-77

Clauset A, Shalizi C R, Newman M E J (2009) Power-Law distributions in empirical data. Society for Industrial and Applied Mathematics (SIAM) review. 51(4):664-703

Corominas J, Mavrouli O, Santana D, Moya J (2012) Simplified approach for obtaining the block volume distribution of fragmental rockfalls. E Eberhardt, C Froese, A K Turner \& S Leroueil (editors). Landslides and engineered slopes. Taylor and Francis. Vol 2: 1159-1164

Crosta G, Frattini P, Fusi F (2007) Fragmentation in the Val Pola rock avalanche, Italian Alps. Journal of Geophysical Research, 112: p. F01006

Dussauge C, Grasso J, Helmstetter A (2003) Statistical Analysis of Rock Fall Volume Distributions: Implications for Rock fall Dynamics. Journal of Geophysical Research B 108 (B6) (2003) 2286, DOI: 10.1029/2001JB000650

Dussauge C, Helmstetter A, Grasso J, Hantz S, Desvarreux P, Jeannin M, Giraud A (2002) Probabilistic approach to rockfall hazard assessment: potential of historical data analysis. Natural Hazards and Earth Systems Science 2:15-26

Dorren, L K A (2003) A review of rockfall mechanics and modeling approaches. Progress in Physical Geography 27 (1):69- 87

Evans S, Hungr O (1993) The assessment of rockfall hazard at the base of talus slopes. Canadian Geotechnical Journal 30:620-636

Firpo G, Salvini R, Francioni M, Ranjith P (2011) Use of Digital Terrestrial Photogrammetry in rocky slope stability analysis by Distinct Elements Numerical Methods. International Journal of rock Mechanics and Mining Sciences 48:1045-1054

Giacomini A, Buzzi O, Renard B \& Giani, G P (2009) Experimental studies on fragmentation of rock falls on impact with rock surfaces. Int J Rock Mech Min Sci 46:708-715

Hantz D, Rossetti J P, Servant F, D'Amato J (2014) Etude de la distribution des blocs dans un éboulement pour l'évaluation de l'aléa. Proceedings of Rock Slope Stability 2014, Marrakesh, Morocco

Hartmann W K (1969) Terrestrial, lunar and interplanetary rock fragmentation. Icarus 2(2):201-213

Hecht-Nielsen, R (1987) Kolmogorov's mapping neural net-work existence theorem. Proceedings of the first IEEE international conference on neural networks. San Diego CA, USA, 11-14 
Hungr O, Leroueil S, Picarelli L (2014) The Varnes classification of landslides types, an update. Landslides 11:167194

Hungr O, Evans S G, Hazzard J (1999) Magnitude and frequency of rock falls and rock slides along the main transportation corridors of southwestern British Columbia. Canadian Geotechnical Journal, 1999, 36(2): 224-238, 10.1139/t98-106

Jaboyedoff, M, Dudt, J P, Labiouse, V (2005) An attempt to refine rockfall hazard zoning based on the kinetic energy, frequency and fragmentation degree. Natural Hazards and Earth System Sciences 5: 621-632

Okura, Y, Kitahara, H, Sammori, T, Kawanami, A (2000) The effects of rockfall volume on runout distance. Engineering Geology 58(2):109-124

Perfect, E (1997) Fractal models for the fragmentation of rocks and soils: a review. Engineering Geology 48:185198

Pickering, G, Bull, J M, Sanderson, D J (1995). Sampling power-law distributions. Tectonophysics 248:1-20

Salciarini, D, Tamagnini, C, Conversini, P (2009) Numerical approaches for rockfall analysis: a comparison, Proceedings of the 18th World IMACS / MODSIM Congress, Cairns, Australia

Schalkoff, R (1997) Artificial neural network, New York: McGraw-Hill

Sturzenegger M, Stead D (2009) Close-range terrestrial digital photogrammetry and terrestrial scanning for discontinuity characterization on rock cuts. Engineering Geology 106:163-182

Turcotte, D (1986) Fractals and Fragmentation. Journal of Geophysical Research 91. NO B2: Pages 1921-1926

Viero, A, Furlanis, S, Squarzoni, C, Teza, G, Galgaro, A, Gianola, P (2012) Dynamics and mass balance of the Cima Una rockfall (Eastern Alps, Italy). Landslides 10:393-408

Wang, Y, Tonon, F (2010) Discrete Element Modelling of Rock Fragmentation upon Impact in Rock Fall Analysis. Rock Mech Rock Eng 44: 23-35

Wu, C (2011) VisualSFM: A visual structure from motion system. URL: http://homes. cs. washington. edu/ ccwu/vsfm, 9

Zhang Z X, Kou S Q, Jiang L G Lindqvist P A (2000) Effects of loading rate on rock fracture: fracture characteristics and energy partitioning. Int J Rock Mech Min Sci 37:745-762 